\title{
Genetic Main Components for Autism Spectrum Disorder Diagnosis
}

\author{
Manuel Ojea Rúa* \\ Department of Analysis and Psychosocial-Educational Intervention, University of Vigo, Spain
}

*Corresponding author: Manuel Ojea Rúa, Department of Analysis and Psychosocial-

Educational Intervention, University of Vigo, Spain.

Received Date: February 04, 2020

Published Date: February 10, 2020

\section{Opinion}

On Scientific Research Institute, that belongs to AutismTRASCOS Association of Ourense (Spain), currently, a research was carried out regarding most significant explanatory predictive components related causal indicators of autism spectrum disorder (ASD), with main aim of detecting the variables that explain the formation of diagnosis criteria and, therefore, to be able establish the most effective key principles for prevention and adaptation of psycho- development, social and educational. Globally, in preliminary conclusions can be affirmed for 200 participants, the most significant components of predictive perspective of this disorder are integrated of presence of genes very specific, which are present during corresponding karyotype studies performance $[1,2]$.

Indeed, previous analysis developed through statistical procedure of linear regression by steps, it concludes with the presence of 3 diagnosis main explanatory components from total of 19 variables (Table 1 ).

Table 1: Regression analysis.

\begin{tabular}{|c|c|c|c|c|c|c|c|c|c|}
\hline \multirow{2}{*}{ Model } & \multirow{2}{*}{$\mathbf{R}$} & \multirow{2}{*}{ R Squared } & \multirow{2}{*}{ Adjusted R Squared } & \multirow{2}{*}{ Error } & \multicolumn{5}{|c|}{ Changes } \\
\hline & & & & & R Squared & $\mathbf{F}$ & Df1 & Df2 & Sig. \\
\hline Karyotype & $.33(\mathrm{a})$ & .11 & .11 & .81 & .11 & 24.71 & 1 & 190 & 00 \\
\hline Gene & $.37(\mathrm{~b})$ & .14 & .13 & .80 & .02 & 5.92 & 1 & 189 & .01 \\
\hline Diagnosis Age & $.40(\mathrm{c})$ & .16 & .14 & .79 & .01 & 4.22 & 1 & 188 & .04 \\
\hline
\end{tabular}

DV: ASD

Firstly, it's formed by "karyotype" variable; secondly by "gene" variable responsible of criteria etiology of disorder diagnosis, within, in order of prevalence, it's remarkable the 15q-11.2 gene, followed by q13 gene. Likewise, with less incidence, it's indicated other genes: the 45XY gene, P16 gene, TCF3 gene, ETV6 gene or fragile $\mathrm{X}$ gene, and it's also important highlight the presence of several genes combination that are interrelated along of karyotypic analysis, related specially to combination between the q11 and q13 genes. The variable third, is composed by "diagnosis-age", that allow conclude so that earlier the diagnosis realization age, detection will be more effective and, hence, future prognosis is more effective.
In summary, these 3 components constitute the most significant main variables of ASD, which are currently being discussed together with other published international research [3].

In multivariate analysis, it's possible observe detailed of explanatory variance of three factors selected by regression analysis to explain main components of ASD diagnosis throughout univariate analysis (Table 2).

These findings are fundamental for application in different action ambit, educational, clinical and social level, since they require agreement with duly structured action protocol, regarding 
successfully realize, both diagnosis process, such as development plan effectiveness adjusted to specific needs presented by people with ASD:

A. Realize a karyotype analysis of neonatal clinical processes or, in high-risk situations, owing to significant family history, it's must develop along prenatal process.

B. Derive to health service to perform the corresponding karyotype in detection of signs or symptoms related with criteria indicated by International Classification DSM-5 [4]: I) significant deficits in interaction and communication social, and II) presence of significant stereotyped or restrictive behaviors.

C. Carrie out a karyotypic analysis, that can best explain the behavior observed for conceptual semantic integration deficits and codification deficits of information processing.

Table 2: Univariate analysis: Dependent Variable: ASD.

\begin{tabular}{|c|c|c|c|c|c|}
\hline Source & Type III Sum of Squares & Df & Mean Square & F & Sig. \\
\hline Corrected Model & $42.33(\mathrm{a})$ & 20 & 2.11 & 3.64 & 0 \\
\hline Intercept & 4.78 & 1 & 4.78 & 8.24 & 0 \\
\hline Diagnosis-age & 4.85 & 4 & 1.21 & 2.09 & .08 \\
\hline Karyotype & 2.08 & 1 & 2.08 & 3.59 & .06 \\
\hline Gene & 5.87 & 5 & 1.17 & 2.02 & .07 \\
\hline Diagnosis-age* karyotype & 2.41 & 3 & .80 & .24 \\
\hline Diagnosis-age* gene & 10.24 & 7 & 1.46 & 2.52 & .01 \\
\hline Karyotype* gene & 00 & 0 & &. &. \\
\hline Diagnosis-age* karyotype* gene & 00 & 171 & .58 & &. \\
\hline Error & 99.28 & 192 & & & \\
\hline Total & 231 & 191 & & & \\
\hline
\end{tabular}

R Squared $=, 299$ (Adjusted R Squared $=, 217$ )

Thus, it's fundamental the concretion of early and effective diagnostic process to adapt the subsequent adapted learning process, since it demands a very learning specific mediating support, as well as the global behavioral adjustment and, therefore, development process effectiveness.

\section{Acknowledgment}

None.

\section{Conflict of interest}

Author declare no conflict of interest.

\section{References}

1. Artemios P, Areti S, Katerina P, Helen F, Eirini T, et al. (2019) Autism Spectrum Disorder and psychiatric comorbidity in a patient with Myhre Syndrome. Journal of Autism and Developmental Disorders 49(7): 30313035.
2. Rubenstein E, Wiggins LD, Schieve LA, Bradley C, DiGuiseppi C, et al. (2019) Associations between parental broader autism phenotype and child Autism Spectrum Disorder phenotype in the study to explore early development. Autism 23(2): 436-448.

3. (2018) 2017 Summary of Advances in Autism Spectrum Disorder Research. US Department of Health and Human Services, Interagency Autism Coordinating Committee; National Institute of Mental Health (NIMH) (DHHS/NIH), Office of Autism Research Coordination (OARC). Washington DC, USA.

4. (2013) American Psychiatric Association. Diagnostic and Statistical Manual of Mental Disorders (DSM-5). Washington, USA. 